\title{
ANALISIS BIAYA DAN PENDAPATAN BUDIDAYAJAMUR TIRAM PUTIH DI (P4S) NUSA INDAH KABUPATEN BOGOR
}

\author{
Hendra Habibi ${ }^{1}$ Siska Fitrianti ${ }^{2}$ \\ ${ }^{1}$ Mahasiswa Prodi Agribisnis, Politeknik Pertanian Negeri Payakumbuh \\ ${ }^{2}$ Staf Pengajar Prodi Agribisnis Politeknik Pertanian Negeri Payakumbuh \\ Email : siskappn@yahoo.com
}

\begin{abstract}
ABSTRAK
Hortikultura merupakan salah satu subsektor pertanian yang menempati posisi penting dalam memberi kontribusi bagi perekonomian Indonesia.Salah satu hasil dari komoditas hortikultura yaitu jamur tiram putih. Jamur adalah tanaman heterotrofik yaitu tanaman yang kehidupannya tergantungpada organisme lain. Jamur tidak bisa melakukan proses fotosintesis sehingga tidak bisa menghasilkan makanan sendiri. Penelitian ini bertujuan untuk menganalisis biaya dan pendapatan di P4S Nusa Indah pada usaha budidaya jamur tiram putih dan mengetahui kelayakan usaha pada jamur tiram putih. Pengamatan dilakukan mulai tanggal 14 April 2016-21 Mei 2016 di P4S Nusa Indah yang berlokasi di kampung Sukamanah RT 02 RW 01 Desa Tamansari, Kecamatan Tamansari, Kabupaten Bogor, Jawa Barat. P4S Nusa Indah memiliki 4 aspek produksi yaitu jamur tiram putih, tanaman hias, kehutanan dan perikanan. Paling menonjol adalah Jamur tiram putih. Metode pengumpulan data yang digunakan adalah pengamatan langsung kelapangan (observasi) dan wawancara dengan pihak terkait dan studi kepustakaan. P4S Nusa Indah melakukan proses budidaya jamur tiram putih sebanyak 12.000 baglog dengan hasil $4.800 \mathrm{~kg}$ jamur tiram putih dengan harga jual Rp.10.000,-/kg. Dari analisa yang dilakukan P4S Nusa Indah memperoleh laba sebesar Rp.6.328.975,- per periode, R/C ratio 1,2 BEP harga Rp.8.681 dan BEP produksi 4.167 kg.
\end{abstract}

Kata Kunci :Jamur tiram putih;Biaya dan Pendapatan.

\section{PENDAHULUAN}

Pertanian adalah suatu jenis produksi yang berlandaskan dari pertumbuhan. Awal kegiatan pertanian mulai terjadi ketika manusia mulai mengambil peranan dalam proses kegiatan tanaman dan hewan serta mengaturnya untuk pemenuhan kebutuhannya. Pembangunan pertanian di bidang pangan khususnya hortikultura pada saat ini ditujukan untuk lebih memantapkan swasembada pangan, meningkatkan pendapatan masyarakat dan memperbaiki keadaan gizi melalui penganekaragaman jenis bahan makanan, hortikultura merupakan salah satu subsektor pertanian yang menempati posisi penting dalam memberi kontribusi bagi perekonomian Indonesia. Salah satu hasil dari komoditas hortikultura yaitu jamur. Jamur merupakan salah satu jamur konsumsi yang bernilai tinggi. Beberapa jenis jamur tiram yang biasa dibudidayakan oleh masyarakat Indonesia yaitu jamur tiram putih (P. Sajor caju) dan jamur tiram abalone (P. Cystidious). Pada dasarnya semua jenis jamur ini memiliki karakteristik yang hampir sama terutama dari segi morfologi, tetapi secara kasar, warna tubuh buah dapat dibedakan antara jenis yang satu dengan yang lain terutama dalam keadaan segar (Susilawati dan Raharjo, 2010).

Jamur tiram (Pleurotos ostreatus) mempunyai kandungan gizi yang cukup besar sehingga bermanfaat bagi kesehatan manusia. Jamur tiram enak dimakan dan dipercaya mempunyai khasiat obat untuk berbagai penyakit seperti lever, diabetes, anemia, sebagai antiviral dan anti kanker, menurunkan kadar kolesterol, meningkatkan daya tahan tubuh terhadap serangan polio dan influenza serta kekurangan gizi. Selain itu, jamur tiram juga dipercaya mampu membantu penurunan berat badan karena berserat tinggi dan membantu pencernaan.

Pusat Pelatihan Pertanian dan Pedesaan Swadaya (P4S) adalah lembaga pelatihan pertanian dan pedesaan yang didirikan, dimiliki, dikelola oleh petani secara swadaya baik perorangan maupun berkelompok dan diharapakan dapat secara langsung berperan aktif dalam pembangunan pertanian melalui pengembangan sumber daya manusia pertanian dalam bentuk pelatihan atau permagangan bagi petani dan masyarakat di wilayahnya. Pada penulisan ini peneliti bertujuan untuk 
Tujuan penelitian ini adalah Mengetahui proses produksi budidaya jamur tiram putih di P4S Nusa Indah dan Menganilisis biaya danpendapatan di P4S Nusa Indah pada usaha budidaya jamur tiram putih serta Mengetahui kelayakan usaha jamur tiram putih di P4S Nusa Indah.

\section{METODE PELAKSANAAN}

Penelitian ini disusun berdasarkan hasil pelaksanaan di Pusat Pelatihan Pertanian Pedesaan Swadaya (P4S) Nusa Indah yang diketuai oleh ibu Cucu Komalasari. P4S Nusa Indah ini berlokasi di Kampung Sukamanah RT 02 RW 01, Desa Tamansari, Kecamatan Tamansari, Kabupaten Bogor, Jawa Barat. Pengamatan ini dimulai pada 14 Maret-21 Mei 2016. Penulisan penelitian ini mencakup teknis budidaya jamur tiram putih, analisis biaya dan pendapatan jamur tiram putih dan kelayakan usaha di Pusat Pelatihan Pertanian Pedesaan Swadaya (P4S) Nusa Indah. Teknik pengumpulan data yang digunakan dalam penelitian ini adalah sebagai berikut :

a. Wawancara adalah proses memperoleh keuntungan /informasi dengan cara Tanya jawab langsung antara penanya atau pewawancara dengan responden. Responden yang diwawancarai adalah pembimbing lapangan serta karyawan.

b. Observasi yaitu pengumpulan data dengan melakukan pengamatan secara langsung kepada obyek yang diteliti.

\section{HASIL DAN PEMBAHASAN}

Pusat Pelatihan Pertanian dan Pedesaan Swadaya (P4S) Nusa Indah awalnya adalah kelompok tani yang berkumpul dan mendirikan wadah Kelompok Wanita Tani (KWT) Nusa Indah. KWT Nusa Indah berdiri pada 17 Juli 1996 dan kemudian pada tahun 1998 berubah menjadi P4S Nusa Indah yang diresmikan oleh Penyuluh Pertanian Kabupaten Bogor.Setelah beberapa tahun P4S Nusa Indah melaksanakan kegiatan yang berperan dalam peningkatan sumber daya manusia pertanian pedesaan, maka pada tahun 2003 dikukuhkan dengan Surat Keputusan Kepala Informasi dan Penyuluhan Pertanian Kabupaten Bogor pada tanggal 17 Juli 2003 dengan Nomor 520.13/242/KIPP/VII/2003, yang diketuai oleh Ibu Cucu Komalasari dengan anggota yang berjumlah 20 orang.

Dibentuknya P4S Nusa Indah dalam rangka menyebarluaskan teknologi dan keterampilan yang dimilikinya dan sebagai mitra pemerintah dalam peningkatan kualitas sumber daya manusia dibidang usaha tani yang berorientasi agribisnis. Pengelola P4S Nusa Indah adalah petani atau kelompok tani yang memenuhi syarat, yaitu mempunyai jiwa kepemimpinan, mampu menjalin kerjasama, mempunyai jiwa sosial yang tinggi, memiliki sarana dan prasarana untuk penyelenggaraan pemagangan dan mampu menularkan kemampuan kepada orang lain.

\section{1). Kegiatan Produksi Budidaya Jamur Tiram Putih}

1. Pemilihan Lokasi

Lokasi budidaya jamur tiram putih berada pada tempat yang lebih tinggi, yaitu sekitar 700 meter dari permukaan laut.

\section{Kubung atau Rumah Jamur}

Kubung adalah rumah khusus untuk jamur yang terbuat dari bambu sebagai tempat untuk pertumbuhan jamur tiram putih. Model atap kubung P4S Nusa Indah menggunakan model atap seperti rumah biasa dengan puncak atap lebih tinggi yaitusekitar 5-6 meter, dengan tinggi dinding 3-4 meter. Bahan untuk dinding yang digunakan oleh P4S Nusa Indah yaitu anyaman bambu dengan alasan mempunyai kelebihan yaitu harga lebih murah dan mempunyai celah-celahsehingga udara bisa masuksedangkan kekurangannya yaitu cepat rusak atau lapuk.

Pada P4S Nusa Indah untuk lantai kubungnya yaitu lantai tanah,Pada kubung inkubasi terdapat enam tingkat rak dengan kapasitas 5.000 baglog. Sedangkan kubung budidaya jamur memiliki lima rak dengan lima tingkat di setiap rak dan kapasitas sebanyak 10.000 baglog. Ukuran rak pada kubung inkubasi rata-rata 5,5 m x 0,75 m dengan jarak setiap tingkat rata-rata adalah $0,6 \mathrm{~m}$ dan ukuran rak 
pada kubung budidaya jamur rata-rata adalah 9,5 m x $1 \mathrm{~m}$ dengan jarak setiap tingkat rata-rata adalah $1 \mathrm{~m}$.

3. Pembuatan Media Tanam

- Pengayakan

Pengayakan adalah proses kegiatan memisahkan atau menyaring serbuk gergaji yang besar dan kecil/halus juga sampah serbuk gergaji sehingga didapatkan serbuk kayu gergaji yang halus dan seragam.

- Pencampuran

Pencampuran serbuk kayu gergaji dengan dedak, kapur dan gipsum disesuaikan dengan takaran untuk mendapatkan komposisi media yang merata. Bahan-bahan yang telah disediakan terlebih dahulu ditimbang dengan berat, serbuk gergaji $(100 \mathrm{~kg})$, dedak $(15 \mathrm{~kg})$, kapur $(2 \mathrm{~kg})$, dan gypsum $(1 \mathrm{~kg})$. Pencampuran bahan dilakukan secara manual dengan tenaga manusia.Setelah itu, bahan-bahan diaduk menggunakan tangan sampai tercampur rata dan diberikan air kurang lebih sebanyak 40-45 \% dari jumlah adonan.Dengan takaran jika adonan dikepal tidak pecah.

- Pemeraman

Pemeraman adalah kegiatan menimbun campuran serbuk gergaji kemudian menutupnya secara rapat dengan menggunakan terpal selama 1 malam.

- Pembuatan Baglog

Pengisian media ke kantong plastic dilakukan dengan cara memasukkan adonan media hasil pengomposan kedalam platik. Kemudian adonan tersebut dipadatkan dengan botol atau bahan lainnya. Media yang kurang padat akan menyebabkan hasil panen kurang optimal karena media cepat busuk sehingga produktifitas akan rendah. Berat media sekitar 1,2 kg per baglog. Setelah media padat, baglog yang sudah terisi tersebut diikat dengan karet.

- Sterilisasi

Sterilisasi adalah suatu proses yang dilakukan untuk menonaktifkan mikroba, baik bakteri, kapang, maupun khamir yang dapat mengganggu pertumbuhan jamur yang ditanam.Sterilisasi dilakukan pada suhu $70^{\circ} \mathrm{C}$ selam5-8 jam.

- Pendinginan

Proses pendinginan ini merupakan suatu upaya menurunkan suhu media tanam setelah disterilkan. Proses pendinginan didalam ruangan selama 8 - 12 jam sebelum diinokulasi.

- Inokulasi bibit

Inokulasi adalah proses pemindahan sejumlah kecil miselia jamur dari biakan induk kedalam media tanam yang telah disediakan. Tujuannya adalah menumbuhkan miselia jamur pada media tanam hingga menghasilkan jamur yang siap panen. Dalam melakukan inokulasi harus dilakukan dengan hati-hati dan cermat.

- Inkubasi

Inkubasi adalah proses penyimpanan atau menempatkan media yang telah diinokulasi pada kondisi ruang tertentu agar miselia jamur tumbuh. Media tanam yang sudah diinokulasi kemudian diangkut ke dalam kubung inkubasi dan disusun rapi pada rak. Media tanam jamur dalam tahap inkubasiakan tampak putih secara merata antara 30-40 hari sejak dilakukan inokulasi. Suhu yang dibutuhkan untuk pertumbuhan miselia jamur adalah $25-30^{\circ} \mathrm{C}$.

- Pemindahan ke tempat budidaya

Media tanam yang sudah berumur $\pm 30-40$ hari atau telah putih oleh miselia jamur berarti sudah siap untuk dilakukan pemindahan ke kubung budidaya dan dilanjutkan dengan tahap penumbuhan tubuh buah jamur dengan cara membuka media tanam (baglog) jamur.

- Pemanenan

Pemanenan dilakukan dengan cara mencabut atau memetik seluruh rumpun jamur tiram putih yang ada. Hal ini dilakukan agar semua bagian jamur tercabut dan tidak meninggalkan sisa yang dapat menyebabkan kebusukan.

- Penyiraman 
Penyiraman dilakukan dengan cara penyemprotan atau pengkabutan dengan menggunakan air bersih yang ditujukan pada ruang kubung dan media tumbuh jamur.

- Pengendalian hama dan penyakit

Hama yang sering terdapat pada budidaya jamur tiram putih pada P4S Nusa Indah adalah tikus, kecoa, tungau, belatung (lalat), kumbangmaupun kutu.Untuk penangan hama dan penyakit yang dilakukan hanya dengan membuang baglog yang sudah rusak atau terkena penyakit agar tidak menular ke baglog yang lain.

- Pengaturan suhu ruangan

Membuka dan menutup pintu dan jendela (ventilasi) kubung dan untuk mengatur suhu dan kelembaban agar sesuai dengan kebutuhan yang ditentukan. Agar pertumbuhan jamur optimal diperlukan suhu ruangan dalam kubung $28-30^{\circ} \mathrm{C}$ dan kelembaban sebesar $50-60 \%$ pada saat inkubasi. Sedangkan suhu pada pembentukan tubuh buah sampai panen berkisar antara $22-28^{\circ} \mathrm{C}$ dengan kelembaban 90-95\%. Apabila kelembaban kurang, maka substrat tanaman akan mengering.

- Penanganan pasca panen

Pada P4S Nusa Indah. Jamur yang sudah dipanen tidak dipotong hingga menjadi bagian per bagian tudung, tetapi hanya dibersihkan kotoran yang menempel di bagian akar dan pangkal batang. Dengan cara tersebut, diamping keberhasilannya lebih terjaga, daya simpan jamur tiram putih akan lebih lama. Kemudian membuang atau memisahkan batang tubuh yang rusak atau terkena penyakit dengan menggunakan pisau cutter. Hal tersebut dilakukan tanpa mencuci jamur tiram putih.Jamur tiram putih ditempatkan pada wadah yang bersih dan diletakkan di suhu kamar dengan temperature $\pm 20^{\circ} \mathrm{C}$. kemudian dilakukan pengemasan menggunakan kantong plastic transparan.

\section{2) Analisis Biaya dan Pendapatan Usaha Jamur Tiram Putih di P4S Nusa Indah}

1. Analisis Biaya Usaha Jamur Tiram Putih di P4S Nusa Indah

Analisis biaya pada usaha jamur tiram putih di P4S Nusa Indah merupakan semua masukan yang terpakai atau dikeluarkan dalam produksi usaha jamur tiram putih seperti : biaya peralatan, biaya bahan, biaya investasi, biaya penyusutan, biaya tenaga kerja, biaya lain-lain (listrik dan air, transportasi, sewa tanah).P4S Nusa Indah mengeluarkan biaya dalam pembuatan kubung jamur serta peralatan yang ada didalam kubung.Kubung jamur yang dibuat di P4S Nusa indah ada 4 kubung yang terdiri dari satu kubung kerja, satu kubung inkubasi, dan dua kubung budidaya.

Bahan baku yang dibutuhkan dalam memproduksi jamur tiram putih adalah: serbuk gergaji, dedak, kapur, gypsum, plastic PP, kayu bakar, karet gelang, cin-cin bambu, bibit, spritus, alcohol, air, kertas Koran, air kelapa muda, korek api.Biaya tenaga kerja yang dikeluarkan dalam produksi usaha jamur tiram putih meliputi biaya tenaga kerja pembuatan kubung jamur dan biaya tenaga kerja borongan dalam pembuatan baglog jamur tiram putih.Peralatan yang digunakan dalam usaha budidaya jamur tiram putih di P4S nusa Indah dalam menghasilkan 12.000 baglog mengalami suatu penurunan nilai yang biasa dimasukkan kedalam biaya penyusutan.Besarnya biaya penyusutan selama 1 periode adalah sebesar Rp. 3.677.025.Biaya listrik pada unit usaha jamur tiram putih di P4S Nusa Indah dalam memproduksi jamur merupakan pengeluaran untuk pembayaran abodemen listrik ditambah dengan penggunaan rata-rata listrik pada mesin Jet Pump air setiap bulannya. Usaha jamur tiram putih membutuhkan kayu bakar untuk proses sterilisasi, untuk itu diperlukan biaya transportasi untuk pengantaran kayu bakar dengan menggunakan mobil Pick Up.Lahan yang digunakan pada usaha jamur tiram putih di P4S Nsa Indah dalam memproduksi jamur tiram putih seluas $500 \mathrm{~m} 2$. Berdasarkan penuturan dari ketua P4S Nusa Indah bahwa sewa lahan di daerah lokasi adalah Rp.3.000.000.

\section{Analisis Pendapatan Usaha Jamur Tiram Putih di P4S Nusa Indah}

Pendapatan yang diperoleh dari usaha budidaya jamur tiram putih di P4S Nusa Indah adalah jamur tiram putih segar, baglog siap panen, pengolahan limbah baglog, dan yang menjadi pendapatan utama dari P4S Nusa Indah adalah jamur tiram putih segar.

Baglog siap panen merupakan pendapatan utama dari P4S Nusa indah pada tahun 2010.Awal mula baglog ini diusahakan atau dijual kepada pengusaha dan investor, baglog yang dijual di P4S Nusa 
Indah adalah baglog yang sudah disterilisasikan dan sudah dilakukan pembibitan dan hanya tinggal menunggu waktu panen.Baglog siap panen ini dijual dengan harga Rp.2.500 / baglog.

\section{3) Analisis Kelayakan Usaha Jamur Tiram Putih di P4S Nusa Indah}

Pembelian Peralatan

Perencanaan pengadaan peralatan dari bahan baku yang efektif dan efisien dapat menjadikan kegiatan produksi berjalan lancar dan dapat meningkatkan hasil dan keuntungan bagi budidaya jamur tiram. P4S Nusa Indah membangun sebanyak 4 kubung yaitu kubung kerja, kubung inkubasi dan 2 kubung budidaya dengan ukuran. Rincian biaya di P4S dapat dilihat pada Tabel 1 dan rincian biaya penyusutan dilihat pada Tabel 2 di bawah ini.

Tabel 1 : Rincian Biaya Investasi Budidaya Jamur Tiram Putih di P4S Nusa Indah

\begin{tabular}{|c|c|c|c|c|c|}
\hline \multicolumn{2}{|c|}{ Komponen Biaya Investasi } & Kebutuhan & Satuan & Harga Beli (Rp) & Nilai (Rp) \\
\hline \multirow{4}{*}{ Bangunan } & Kubung budidaya & 2 & $7 \times 10 \mathrm{~m}$ & 8.000 .000 & 16.000 .000 \\
\hline & Kubung inkubasi & 1 & $3 \times 5 \mathrm{~m}$ & 3.000 .000 & 3.000 .000 \\
\hline & Kubung kerja & 1 & $5 \times 7 \mathrm{~m}$ & 6.000 .000 & 6.000 .000 \\
\hline & \multicolumn{3}{|c|}{ Total inevestasi bangunan } & & 25.000 .000 \\
\hline \multirow{21}{*}{ Peralatan } & Drum besar & 1 & Unit & 4.500 .000 & 4.500 .000 \\
\hline & Drum kecil & 1 & Unit & 100.000 & 100.000 \\
\hline & Pompa air & 1 & Unit & 300.000 & 300.000 \\
\hline & Selang & 20 & meter & 10.000 & 200.000 \\
\hline & Karung goni & 300 & Unit & 1.000 & 300.000 \\
\hline & Bak air & 1 & Unit & 100.000 & 100.000 \\
\hline & Sekop & 1 & Unit & 30.000 & 30.000 \\
\hline & Ember & 4 & Unit & 35.000 & 140.000 \\
\hline & Gayung & 1 & Unit & 5.000 & 5.000 \\
\hline & Terpal & 6 & meter & 10.000 & 60.000 \\
\hline & Pisau cutter & 2 & Unit & 10.000 & 20.000 \\
\hline & Timbangan $10 \mathrm{~kg}$ & 1 & Unit & 195.000 & 195.000 \\
\hline & Ayakan serbuk & 1 & Unit & 30.000 & 30.000 \\
\hline & Handsprayer & 2 & Unit & 20.000 & 40.000 \\
\hline & Botol & 5 & Unit & 1.000 & 5.000 \\
\hline & Spatula & 2 & Unit & 10.000 & 20.000 \\
\hline & Lampu laminar & 1 & Unit & 15.000 & 15.000 \\
\hline & Cangkul & 1 & Unit & 30.000 & 30.000 \\
\hline & Sendok & 5 & Unit & 15.000 & 75.000 \\
\hline & Gas & 3 & Unit & 150.000 & 450.000 \\
\hline & Bak panen & 3 & Unit & 15.000 & 45.000 \\
\hline \multicolumn{3}{|c|}{ Total investasi peralatan } & & & 6.660 .000 \\
\hline \multicolumn{3}{|c|}{ Total biaya Investasi } & & & 31.660 .000 \\
\hline
\end{tabular}

Tabel 2. Rincian Biaya Penyusutan Budidaya Jamur Tiram Putih di P4S Nusa Indah selama 4 bulan

\begin{tabular}{|c|c|c|c|c|c|c|}
\hline \multicolumn{2}{|c|}{ Komponen Biaya Investasi } & $\begin{array}{c}\text { Biaya } \\
\text { Investasi } \\
(\mathbf{R p})\end{array}$ & $\begin{array}{l}\text { Umur } \\
\text { Ekonomis } \\
\text { (Th) }\end{array}$ & $\begin{array}{c}\text { Nilai } \\
\text { Sisa (Rp) }\end{array}$ & $\begin{array}{c}\text { Penyusustan } \\
\text { per Tahun } \\
\text { (Rp) }\end{array}$ & $\begin{array}{l}\text { Penyusutan } \\
\text { per periode } \\
(\mathbf{R p})\end{array}$ \\
\hline \multirow{4}{*}{ Bangunan } & Kubung budidaya & $16,000,000$ & 10 & $1,600,000$ & $1,440,000$ & 480,000 \\
\hline & Kubung inkubasi & $3,000,000$ & 10 & 300,000 & 270,000 & 90,000 \\
\hline & Kubung kerja & $6,000,000$ & 10 & 600,000 & 540,000 & 180,000 \\
\hline & \multicolumn{3}{|c|}{ Total Penyusutan Bangunan } & & $2,250,000$ & 750,000 \\
\hline \multirow{3}{*}{ Peralatan } & Drum besar & $4,500,000$ & 5 & 225,000 & 855,000 & 285,000 \\
\hline & Drum kecil & 100,000 & 5 & 5,000 & 19,000 & 6,333 \\
\hline & Pompa air & 300,000 & 5 & 15,000 & 57,000 & 19,000 \\
\hline
\end{tabular}




\begin{tabular}{crrrrr}
\hline Komponen Biaya Investasi & $\begin{array}{c}\text { Biaya } \\
\text { Investasi } \\
(\mathbf{R p})\end{array}$ & $\begin{array}{c}\text { Umur } \\
\text { Ekonomis } \\
\text { (Th) }\end{array}$ & $\begin{array}{c}\text { Nilai } \\
\text { Sisa (Rp) }\end{array}$ & $\begin{array}{c}\text { Penyusustan } \\
\text { per Tahun } \\
\text { (Rp) }\end{array}$ & $\begin{array}{c}\text { Penyusutan } \\
\text { per periode } \\
\text { (Rp) }\end{array}$ \\
\hline Selang & 200,000 & 3 & 0 & 66,667 & 22,222 \\
Karung goni & 300,000 & 3 & 0 & 100,000 & 33,333 \\
Bak air & 100,000 & 5 & 5,000 & 19,000 & 6,333 \\
Sekop & 30,000 & 5 & 1,500 & 5,700 & 1,900 \\
Ember & 140,000 & 3 & 0 & 46,667 & 15,556 \\
Gayung & 5,000 & 3 & 0 & 1,667 & 556 \\
Terpal & 60,000 & 3 & 0 & 20,000 & 6,667 \\
Pisau cutter & 20,000 & 0 & 0 & - & - \\
Timbangan 10 kg & 195,000 & 10 & 9,750 & 18,525 & 6,175 \\
Ayakan serbuk & 30,000 & 5 & 1,500 & 5,700 & 1,900 \\
Handsprayer & 40,000 & 5 & 2,000 & 7,600 & 2,533 \\
Botol & 5,000 & 0 & 250 & - & - \\
Spatula & 20,000 & 5 & 1,000 & 3,800 & 1,267 \\
Lampu laminar & 15,000 & 3 & 0 & 5,000 & 1,667 \\
Cangkul & 30,000 & 5 & 1,500 & 5,700 & 1,900 \\
Sendok & 75,000 & 3 & 0 & 25,000 & 8,333 \\
Gas & 450,000 & 3 & 0 & 150,000 & 50,000 \\
Bak panen & 45,000 & 3 & 0 & 15,000 & 5,000 \\
\hline Total Penyusutan Peralatan & & & & $1,427,025$ & 475,675 \\
\hline Total Biaya Penyusutan & & & & $\mathbf{3 , 6 7 7 , 0 2 5}$ & $\mathbf{1 , 2 2 5 , 6 7 5}$ \\
\hline
\end{tabular}

\section{4) Penyediaan Bahan Baku}

Bahan baku merupakan bahan mentah yang diolah dan dapat dimanfaatkan sebagai sarana produksi dalam suatu industri. Ketersediaan bahan baku secara cukup dan berkelanjutan akan menjamin suatu perusahaan untuk bisa berproduksi dalam waktu yang relatif lama.

Bahan baku dapat diperoleh dengan mudah karena ketersediaan maupun harga yang terjangkau sehingga tidak menjadi suatu hambatan bagi perusahaan. Kebutuhan bahan baku selama 4 bulan dapat dilihat pada Tabel 3 di bawah ini

Tabel 3. Kebutuhan Bahan Baku Budidaya Jamur 12.000 Baglog Selama 4 Bulan

\begin{tabular}{llccrr}
\hline No & Nama bahan & Kebutuhan & Satuan & Harga (Rp) & Nilai (Rp) \\
\hline 1 & Serbuk gergaji & 900 & Karung & 3.500 & 3.150 .000 \\
2 & Dedak & 1.200 & $\mathrm{Kg}$ & 3.700 & 4.440 .000 \\
3 & Kapur CaCo3 & 144 & $\mathrm{Kg}$ & 6.000 & 864.000 \\
4 & Gypsum & 72 & $\mathrm{Kg}$ & 6.000 & 432.000 \\
5 & Karet & 3 & $\mathrm{Kg}$ & 64.000 & 192.000 \\
6 & Plastik & 60 & $\mathrm{Kg}$ & 30.000 & 1.800 .000 \\
7 & Bibit & 840 & Botol & 7.500 & 6.300 .000 \\
8 & Kayu bakar & 2 & Mobil & 300.000 & 600.000 \\
9 & Cincin & 12.000 & Buah & 50 & 600.000 \\
10 & Koran & 12 & Kg & 3.000 & 36.000 \\
11 & Alkohol & 6 & Liter & 30.000 & 180.000 \\
12 & Spritus & 6 & Liter & 35.000 & 210.000 \\
13 & Air kelapa & 60 & Liter & 7.000 & 420.000 \\
\hline \multicolumn{7}{l}{ Total } & & & & $\mathbf{1 9 . 2 2 4 . 0} \mathbf{0 0}$ \\
\hline
\end{tabular}

\section{5) Biaya Tenaga Kerja}

Biaya Tenaga Kerja yang dikeluarkan dalam budidaya jamur tiram putih dapat dilihat pada Tabel 4 di bawah ini 
Tabel 4. Biaya Tenaga Kerja

\begin{tabular}{llclrr}
\hline No & \multicolumn{1}{c}{ Jenis Kegiatan } & Kebutuhan & Satuan & Upah (Rp) & \multicolumn{1}{c}{ Nilai (Rp) } \\
\hline 1 & Tenaga kerja bangunan & 2 & HKO & 2.700 .000 & 5.400 .000 \\
2 & Tenaga kerja Produksi baglog & 12000 & Baglog & 500 & 6.000 .000 \\
\hline & & & & $\mathbf{1 1 . 4 0 0 . 0 0}$ \\
\hline
\end{tabular}

\section{6) Biaya Lain-lain.}

Biaya lain yang dikeluarkan dalam budidaya jamur tiram putih dapat dilihat pada Tabel 5 di bawah ini

Tabel 5. Biaya Lain Yang Dibutuhkan

\begin{tabular}{llclrr}
\hline No & Komponen biaya & Jumlah & Satuan & Harga per satuan (Rp) & \multicolumn{1}{c}{ Nilai (Rp) } \\
\hline 1 & Listrik dan air & 4 & bulan & 30.000 & 120.000 \\
2 & Sewa tanah & 12 & bulan & 250.000 & 3.000 .000 \\
3 & Transportasi & 17 & Kali/mobil & 250.000 & 4.250 .000 \\
\hline & jumlah & & & & $\mathbf{7 . 3 7 0 . 0 0 0}$ \\
\hline
\end{tabular}

\section{7) Rekapitulasi biaya}

Rekapitulasi seluruh biaya lain yang dikeluarkan dalam budidaya jamur tiram putih dapat dilihat pada Tabel 6 di bawah ini

Tabel 6. Rekapitulasi Biaya

\begin{tabular}{llr}
\hline No & \multicolumn{1}{c}{ Jenis pembiayan } & Total per periode (Rp) \\
\hline 1 & Biaya penyusutan & 3.677 .025 \\
2 & Biaya bahan & 19.224 .000 \\
3 & Biaya tenaga kerja & 11.400 .000 \\
4 & Biaya lain-lain & 7.370 .000 \\
\hline & Jumlah & 41.671 .025 \\
\hline
\end{tabular}

\section{8) Produksi}

Hasil Produksi Jamur tiram putih di P4S Nusa Indah dapat dilihat pada Tabel 7 di bawah ini

Tabel 7. Produksi Jamur Tiram Putih Di P4S Nusa Indah

\begin{tabular}{cccr}
\hline Produksi & Jumlah & Produksi / Baglog & \multicolumn{1}{c}{ Total Produksi } \\
\hline Jamur tiram putih & 12.000 baglog & $0.4 \mathrm{Kg}$ & $4.800 \mathrm{Kg}$ \\
\hline Jumlah & & & $\mathbf{4 . 8 0 0 ~} \mathbf{~ K g}$ \\
\hline
\end{tabular}

\section{9) Pendapatan}

Hasil produksi atau pendapatan jamur tiram putih dalam satu periode dapat dilihat pada Tabel 8 di bawah ini

Tabel 8. Pendapatan Jamur Tiram Putih

\begin{tabular}{rccr}
\hline Jenis Produk & Jumlah $(\mathbf{K g})$ & Harga $/ \mathbf{K g}$ & \multicolumn{1}{c}{ Nilai (Rp) } \\
\hline Jamur Tiram Putih & 4.800 & 10,000 & 48.000 .000 \\
\hline Jumlah & & & $\mathbf{4 8 . 0 0 0 . 0 0 0}$ \\
\hline
\end{tabular}

10) Analisis biaya dan pendapatan

Analisa laporan laba rugi dari jamur tiram putih dapat dilihat pada Tabel 9 di bawah ini 
Tabel 9. Analisa Laporan Laba Rugi

\begin{tabular}{llrr}
\hline No & Keterangan & Jumlah (Rp) & Total (Rp) \\
\hline 1 & Pendapatan & & \\
& Utama & 48.000 .000 & \\
\hline & Total pendapatan & & \\
\hline 2 & Biaya & & \\
& Penyusutan & 3.677 .025 & \\
& Biaya bahan baku & 19.224 .0000 .000 \\
& Biaya tenaga kerja & 11.400 .000 & \\
& Biaya lain-lain & 7.610 .000 & \\
\hline & Total Biaya & & 61.671 .025 \\
\hline 3 & Laba & & 6.328 .975 \\
\hline
\end{tabular}

a. Analisa finansial

1. Pendapatan satu periode produksi $=\mathrm{Rp} .48 .000 .000$

2. Biaya satu periode produksi $=\mathrm{Rp} .41 .671 .025$

3. Laba satu periode produksi $=\mathrm{Rp} .6 .328 .975$

b. $\mathrm{R} / \mathrm{C}$ ratio

$$
\begin{aligned}
& \mathrm{R} / \mathrm{C} \text { ratio }=\frac{\text { Pendapatan }}{\text { Total bIaya }} \\
& =\frac{48.000 .000}{41.671 .025} \\
& =1,2
\end{aligned}
$$

Kondisi ini menggambarkan bahwa usaha budidaya jamur tiram putih layak untuk diusahakan karena nilai $\mathrm{R} / \mathrm{C}$ rationya besar dari 1. Usaha jamur tiram putih P4S Nusa Indah dapat dikatakan efisien karena memiliki nilai rasio penerimaan atas biaya yang lebih dari satu ( R/C Ratio> 1) sehingga kegiatan usaha jamur tiram putih layak karena memberikan penerimaan lebih besar dari pada pengeluarannya.

c. BEP

- BEP Harga = $=\frac{\text { Biaya Operasional }}{\text { Tota hasil panen }}$

$$
\begin{aligned}
& =\frac{41.671 .025}{4.800 \mathrm{~kg}} \\
& =\text { Rp. } 8.681
\end{aligned}
$$

Yang artinya dengan memelihara 10.000 baglog jamur tiram putih, maka titik balik modal tercapai jika harga jamur Rp.8.681/kg.

- BEP Produksi $=\frac{\text { Biaya Operasional }}{\text { harga jamur per } \mathrm{kg}}$

$$
\begin{aligned}
& =\mathrm{Rp} \cdot \frac{41.671 .025}{10.000 / \mathrm{kg}} \\
& =4.167 \mathrm{~kg}
\end{aligned}
$$

Dengan harga jual Rp 10.000/kg, titik balik modal tercapai jika jamur yang terjual sebanyak

\section{$4.167 \mathrm{~kg}$}

\section{KESIMPULAN}

P4S Nusa Indah melakukan proses budidaya jamur tiram putih dimulai dari pemilihan lokasi sampai proses pemanenan yang mana proses budidaya jamur tiram putih ini membutuhkan waktu selama 4 bulan. 
Dari analisis biaya dan pendapatan yang dilakukan dapat diketahui bahwa usaha jamur tiram putih P4S Nusa Indah mengeluarkan biaya sebesar Rp.41.671.025 dan pendapatan dari usaha jamur tiram putih sebesar Rp.48.000.000 sehingga memperoleh laba/keuntungan yang bernilai sebesar Rp.6.328.975 per periode dengan skala produksi 12.000 baglog sehingga dapat disimpulkan bahwa usaha jamur tiram putih ini menguntungkan.

Usaha jamur tiram putih di P4S Nusa Indah layak untuk dilanjutkan mengingat perolehan pendapatan yang menguntungkan. Hal ini juga ditunjang oleh beberapa hasil analisis usaha, yaitu analisis perbandingan penerimaan atas biaya ( $\mathrm{R} / \mathrm{C}$ ratio) 1,2 dan titik impas (break even point) dimana BEP harga Rp.8.681 dari harga jual Rp.10.000 dan BEP produksi $4.167 \mathrm{~kg}$ dari $4.800 \mathrm{~kg}$ produksidan ini menyatakan bahwa usaha jamur tiram putih tersebut menguntungkan dan memberikan manfaat sehingga dapat digunakan sebagai salah satu indikator kelayakan suatu usaha.

\section{DAFTAR PUSTAKA}

Fadilah, Nur. 2010. Tips Budidaya Jamur Tiram. genius Publisher .Yogyakarta

Susilawati dan raharjo. 2010. Budidaya Jamur Tiram (pleourotus ostreatus var florida) yang Ramah Lingkungan. BPTP Sumatera Selatan.

Zulfahmi, muhammad. 2011. Analisis Biaya dan Pendapatan Usaha Jamur Tiram Putih Model Pusat Pelatihan Pertanian Perdesaan Swadaya (P4S) Nusa Indah [Skripsi]. Jakarta: UIN, Fakultas Sains dan Teknologi. 